\title{
Photoperiodic suppression of gonadotrophin secretion in castrated male hamsters
}

\author{
H. F. Urbanski and S. M. Simpson \\ A.R.C. Research Group on Photoperiodism \& Reproduction, Department of Zoology, \\ The University, Bristol BS8 IUG, U.K.
}

\begin{abstract}
Summary. Male golden hamsters were transferred from long to short days and castrated on the day of transfer (Group SP0) or 1, 2 or 3 weeks afterwards (Groups SP1, SP2 \& SP3). Animals in Group LP were castrated and maintained on long days. After 7 weeks of short days, plasma levels of LH and FSH were low in Groups SP1, SP2, and SP3. In Group SP0 LH output was also low and FSH secretion, although greater than in Groups SP1, SP2 and SP3, was lower than in the long-day controls (Group LP). This photoperiodic control of gonadotrophin secretion in castrated hamsters raises doubts about the significance of hypothetical alterations in hypothalamo-pituitary sensitivity to sex steroids.
\end{abstract}

\section{Introduction}

It is well established that changes in photoperiod induce marked alterations in the neuroendocrine activity of many seasonally breeding animals. Just how photoperiodic information is transduced into a particular pattern of gonadotrophin secretion is unclear but when Suffolk ewes and red deer stags are gonadectomized alterations in the photoperiod no longer affect the mean serum LH values (Legan, Karsch \& Foster, 1977; Lincoln \& Kay, 1979). These observations appear to be consistent with the view that photoperiodic control of gonadotrophin secretion is mediated via the gonadal negative feedback system, the photoperiod modulating the sensitivity of the hypothalamo-pituitary axis to the feedback effects of sex steroids. On the other hand, in many other animals, e.g. snowshoe hares, rams, mares, Japanese quail and Djungarian hamsters, gonadotrophin output does respond to photoperiodic manipulations after gonadectomy (Davis \& Meyer, 1973; Pelletier \& Ortavant, 1975; Garcia \& Ginther, 1976; Urbanski \& Follett, 1982; Simpson, Follett \& Ellis, 1982). In the castrated golden hamster the photoperiodic responses suggest that perhaps both direct and feedbackmediated photoperiodic mechanisms are operative. Castration of hamsters with regressed testes leads to only a slight elevation of serum gonadotrophin levels if the animals are maintained in a short-day photoperiod, but there is a dramatic increase when they are subsequently transferred to long days. A large increase is also observed when sexually mature hamsters are castrated and maintained in long days. These findings, therefore, demonstrate a direct photoperiodic modulation of gonadotrophin secretion (Turek, Elliott, Alvis \& Menaker, 1975; Tamarkin, Hutchison \& Goldman, 1976; Ellis \& Turek, 1980). Consequently, one might expect that the transfer of castrated hamsters from long to short days should induce a decrease in gonadotrophin output; but the results have been variable (Turek et al., 1975; Turek, 1977; Tate-Ostroff \& Stetson, 1978; Ellis \& Turek, 1979, 1980). This has led to the idea that while direct photoperiodic effects are involved in regulating the onset of breeding season in the 
hamster, its termination might be to some extent dependent upon indirect, steroid-dependent effects (review: Turek \& Ellis, 1981). The present study was undertaken to examine further this apparent change in the relative importance of the mechanisms modulating gonadotrophin secretion.

\section{Materials and Methods}

Male golden hamsters (Mesocricetus auratus) were purchased when 10 weeks old (G. Gore, Laindon, U.K.) and maintained in a long photoperiod of $14 \mathrm{~h}$ light per day (14L:10D, lights on $04: 00 \mathrm{~h}$ ). Hamster breeding diet (Oxoid) and water were available ad libitum. At about 20 weeks of age, 4 groups of animals were transferred to a short photoperiod (9L:15D, lights on 08:00 h) and castrated under pentobarbitone sodium anaesthesia either on the day of transfer (Group SP0) or 1, 2 or 3 weeks afterwards (Groups SP1, SP2, and SP3). Animals in a fifth group (LP) were castrated at the same time as those in Group SP0 and were maintained in 14L:10D throughout the experiment. At weekly intervals, $0.5 \mathrm{ml}$ blood samples were collected by cardiac puncture under halothane anaesthesia, and the plasma was stored frozen. Initially, there were 7 hamsters within each experimental group ( 3 or 4 animals per cage), but because of mortalities following routine serial cardiac puncture numbers were progressively reduced and only those animals surviving until at least week 7 of treatment are included in the results.

Plasma follicle-stimulating hormone (FSH) was measured by radioimmunoassay using a rat FSH kit supplied by the National Institute of Arthritis, Metabolism and Digestive Diseases (NIAMDD) with standard FSH-RP-1. Plasma luteinizing hormone (LH) was measured by the ovine-ovine system of Niswender, Midgley, Monroe \& Reichert (1968) with rat standard LH-RP-1. Both radioimmunoassays have been validated for use in the hamster (Berndtson \& Desjardins, 1974; Blake, Norman \& Sawyer, 1973). A single assay was performed for each hormone and the intra-assay coefficients of variation, determined by including 10 samples from a plasma pool, were $9 \%$ for FSH and $6 \%$ for LH. The minimum detectable plasma concentrations of FSH and LH were 20 and $2 \mathrm{ng} / \mathrm{ml}$, respectively.

Results were analysed by using paired Student's $t$ test and analysis of variance.

\section{Results}

By 1 week after castration, all animals had shown the expected increase in plasma FSH levels, although a significant rise in plasma LH was seen only in Groups LP and SP0 (Text-fig. 1). At this stage, levels of neither FSH nor LH differed significantly amongst the 5 groups $(P>0.05)$. Subsequently, hormone concentrations increased further in Group LP but fell dramatically in Groups SP1, SP2 and SP3. In Group SP0 there was a fall in plasma LH values but not in FSH. At 7 weeks after transfer, plasma LH levels were significantly lower in Groups SP0, SP1, SP2 and SP3 $(\mathrm{N}=6,4,7$ and 5 respectively) than in Group LP $(\mathrm{N}=7)(P<0.01)$. Plasma FSH levels in Groups SP1, SP2 and SP3 were also significantly lower than those in Group LP $(P<$ $0.01)$; values in Group SP0 were lower than those in Group LP $(P<0.05)$, but higher than those in the other 3 groups $(P<0.05)$. At the end of the experiment, 9 weeks after transfer to short days, the mean ( \pm s.e.m.) plasma concentrations of FSH and LH in surviving hamsters from Groups SP1, SP2 and SP3 were $315 \pm 55 \mathrm{ng} \mathrm{FSH} / \mathrm{ml}$ and $25 \pm 5 \mathrm{ng} \mathrm{LH} / \mathrm{ml}(\mathrm{N}=11)$. These values were different from those of hamsters in Group LP $(4368 \pm 188 \mathrm{ng}$ FSH/ml and $982 \pm 187 \mathrm{ng} \mathrm{LH} / \mathrm{ml}, \mathrm{N}=6)$. Animals in Group SP0 $(\mathrm{N}=5)$ had an intermediate position with relatively high FSH $(2055 \pm 1004 \mathrm{ng} / \mathrm{ml})$ and low $\mathrm{LH}(189 \pm 67 \mathrm{ng} / \mathrm{ml})$ levels. 


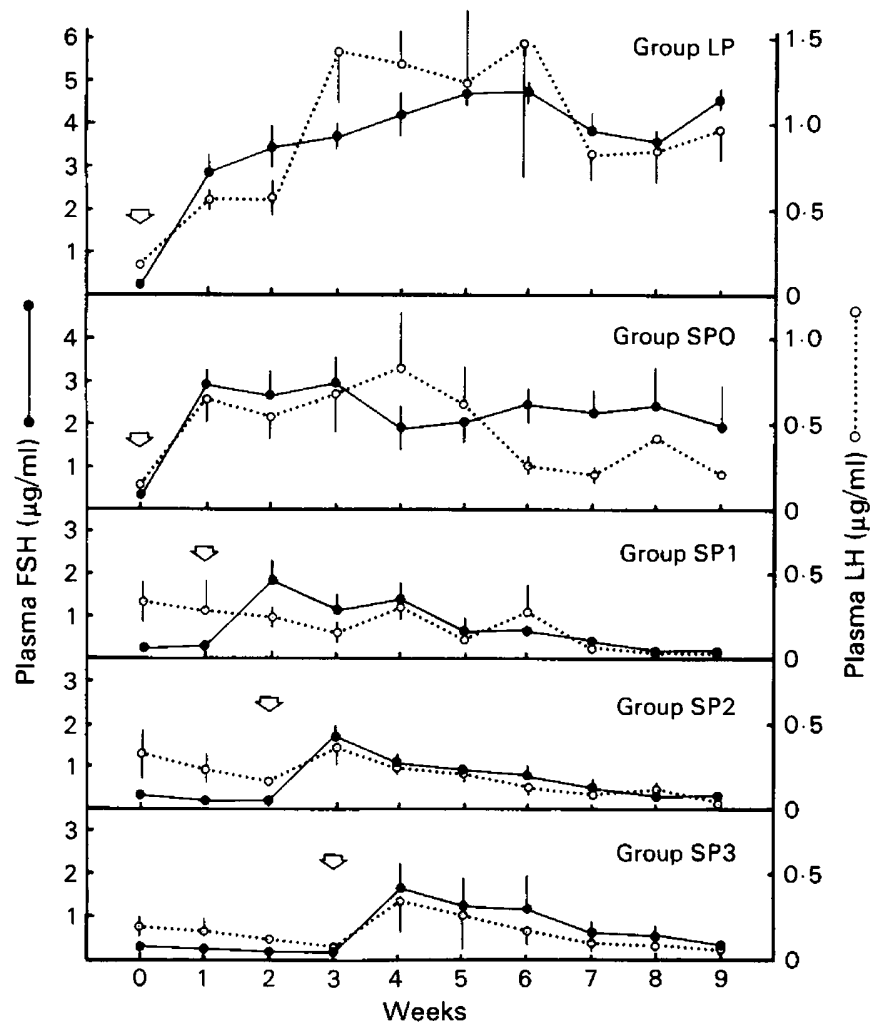

Text-fig. 1. Concentrations of plasma FSH and LH in male hamsters maintained in 14L:10D (Group LP) or transferred at time 0 from 14L:10D to 9L:15D (Groups SP0, SP1, SP2 and SP3); the arrows indicate the times of castration. Between Weeks 0 and 8 the number of animals in each group was 7 (LP), 6 (SP0), 4 (SP1), 7 (SP2), and 5 (SP3), and during Weeks 8 and 9, was $7,5,3,4$ and 4 , respectively. Points represent means, and s.e.m. are shown by vertical bars unless they fall within the symbol width.

\section{Discussion}

The results showed that when hamsters were castrated and maintained in a long-day photoperiod plasma LH and FSH concentrations increased dramatically and then remained elevated for the duration of the experiment. Animals which were transferred to short days at the time of castration showed a similar increase over the first few weeks but this became attenuated so that after 7 weeks plasma gonadotrophin levels were lower than in the long-day group. This finding that short photoperiods can, to some extent, suppress gonadotrophin output in castrated hamsters is consistent with some previously reported data (Turek et al., 1975; Tate-Ostroff \& Stetson, 1978; Ellis \& Turek, 1980). The more interesting finding in the present experiment, however, was that when castration was delayed until the animals had experienced at least 1 week of short days, the suppressive effects of short photoperiods were even more pronounced: at the end of the experiment plasma levels of FSH were much lower in Groups SP1, SP2 and SP3 than in Group SPO. It seems then that castration performed during a long-day photoperiod in some way interfered with or masked the photoperiodic suppression of gonadotrophin secretion induced by transfer to short days, and perhaps could account for other instances in which complete suppression was not observed (Turek, 1977; Ellis \& Turek, 1979, 1980). Just how the 
photoperiodic response of hamsters is affected by castration is unclear but one possible explanation is that the photoperiodic 'switch' that changes the neuroendocrine activity from a long day to a short day mode includes a pathway which involves gonadal steroids, so that castration performed before transfer to short days precludes a complete reduction in secretion. Once the photoperiodic switch has operated, however, gonadal steroids are not required to bring about the subsequent reduction in gonadotrophin output, indicated by the response of the hamsters castrated after transfer from long to short days. Alternatively, the hyperactivity of the hypothalamo-pituitary axis that follows the removal of negative feedback under conditions of long-day photoperiodic drive lead to a pathological condition in which the high rate of secretion cannot be fully suppressed by short photoperiods, while the effect of castration during short days, when the photoperiodic drive is reduced, will not induce such a response. The pathological condition might arise for a number of reasons; hyperactivity of the LH-RH neurones and the hypertrophy of the pituitary gland are just two possibilities. It has been previously suggested that the gonadotrophin content of the pituitary gland in castrated 'long-day' hamsters might be so high that hormones 'leak out' even when the animals are transferred to short photoperiods (Turek et al., 1975). Full explanation of the effects of castration on the hamster's photoperiodic response requires further experimentation. Castration of hamsters within 1 day of transfer to short days can lead to a variety of responses: the short-day suppression of gonadotrophin output may be complete or only partial, or absent altogether (see Turek et al., 1975; Turek, 1977; Ellis $\&$ Turek, 1980). This suggests that it is unlikely to be the time of castration relative to the operation of a steroid-dependent photoperiodic switch which determines the subsequent response to short days. Nevertheless, for these published data to remain consistent with the alternative concept of a castration-induced pathological condition, other possible influencing factors besides photoperiod must be considered, such as the age of the animals, the ambient temperature, housing density, bleeding frequency and the way in which the photoperiodic clock was entrained by the chosen lighting regimens.

While the causes underlying the inconsistency of response to short days remain unknown, the present data confirm that gonadotrophin output in the castrated hamster can be fully suppressed in a short-day photoperiod. As the negative feedback effects of adrenal and dietary steroids are unimportant to gonadotrophin secretion in the castrated hamster (Bitman \& Goldman, 1979; Ellis \& Turek, 1980) this emphasizes that at the end of the breeding season as well as at its onset there is modulation of gonadotrophin secretion which is independent of the continuous presence of sex steroids. It is a matter of speculation whether there are also photoperiodically induced changes in sensitivity to steroids at these times that act as additional modulatory factors. That a given dose of testosterone is more effective in suppressing $\mathrm{LH}$ and FSH output in castrated hamsters in short days than in long days can be regarded as an indication of differences in sensitivity (Turek, 1977; Ellis \& Turek, 1979). However, there may not be changes in actual sensitivity at, say the receptor level, only an apparent difference, as the direct effects of daylength on gonadotrophin secretion will inevitably mean that hypothalamopituitary activity will require more negative feedback to oppose it during long days than during short days (Goodman \& Karsch, 1981; Turek \& Ellis, 1981; Urbanski \& Follett, 1981). There could be actual changes in sensitivity in hamsters but these have yet to be convincingly demonstrated and, moreover, because photoperiod does alter gonadotrophin secretion directly, their significance is questionable.

We thank Mrs D. Bond for her expert technical assistance; Dr G. D. Niswender for the LH-RIA antisera; and the NIAMDD Rat Pituitary Hormone Distribution Program for the FSH RIA kit and the LH standard. 


\section{References}

Berndtson, W.E. \& Desjardins, C. (1974) Circulating LH and FSH levels and testicular function in hamsters during light deprivation and subsequent photoperiodic stimulation. Endocrinology 95, 195205.

Bittman, E.L. \& Goldman, B.D. (1979) Serum levels of gonadotrophins in hamsters exposed to short photoperiods: effects of adrenalectomy and ovariectomy. J. Endocr. 83, 113-118.

Blake, C.A., Norman, R.L. \& Sawyer, C.H. (1973) Validation of an ovine-ovine $\mathrm{LH}$ radioimmunoassay for use in the golden hamster. Biol. Reprod. 8, 299-305.

Davis, G.J. \& Meyer, R.K. (1973) Seasonal variation in LH and FSH of bilaterally castrated snowshoe hares. Gen. comp. Endocr. 20, 61-68.

Ellis, G.B. \& Turek, F.W. (1979) Time course of the photoperiod-induced change in sensitivity of the hypothalamic-pituitary axis to testosterone feedback in castrated male hamsters. Endocrinology 104, $625-630$.

Ellis, G.B. \& Turek, F.W. (1980) Photoperiodic regulation of serum luteinizing hormone and folliclestimulating hormone in castrated and castratedadrenalectomized male hamsters. Endocrinology 106, 1338-1344.

Garcia, M.C. \& Ginther, OJ. (1976) Effects of ovariectomy and season on plasma luteinizing hormone in mares. Endocrinology 98, 958-962.

Goodman, R.L. \& Karsch, F.J. (1981) A critique of the evidence on the importance of steroid feedback to seasonal changes in gonadotrophin secretion. $J$. Reprod. Fert., Suppl. 30, 1-13.

Legan, S.J., Karsch, F.J. \& Foster, D.L. (1977) The endocrine control of seasonal reproductive function in the ewe: a marked change in the response to the negative feedback action of estradiol on luteinizing hormone secretion. Endocrinology 101, 818-824.

Lincoln, G.A. \& Kay, R.N.B. (1979) Effects of season on the secretion of $\mathrm{LH}$ and testosterone in intact and castrated red deer stags (Cervus elaphus). J. Reprod. Fert. 55, 75-80.
Niswender, G.D., Midgley, A.R., Jr, Monroe, S.E. \& Reichert, L.E., Jr (1968) Radioimmunoassay for rat luteinizing hormone with antiovine LH serum and ovine LH- ${ }^{131}$ I. Proc. Soc. exp. Biol. Med. 128 , $807-811$.

Pelletier, J. \& Ortavant, R. (1975) Photoperiodic control of $\mathrm{LH}$ release in the ram. I. Influence of increasing and decreasing light photoperiods. Acta endocr., Copenh. 78, 435-441.

Simpson, S.M., Follett, B.K. \& Ellis, D.H. (1982) The modulation by photoperiod of gonadotrophin secretion in intact and castrated Djungarian hamsters. J. Reprod. Fert. 66, 243-250.

Tamarkin, L., Hutchison, J.S. \& Goldman, B.D. (1976) Regulation of serum gonadotropins by photoperiod and testicular hormone in the Syrian hamster. Endocrinology 99, 1528-1533.

Tate-Ostrofi, B.A. \& Stetson, M.H. (1978) The photoperiodic "gonadal" response in castrated male hamsters. Am. Zool. 18, 572.

Turek, F.W. (1977) The interaction of the photoperiod and testosterone in regulating serum gonadotropin levels in castrated male hamsters. Endocrinology 101, 1210-1215.

Turek, F.W. \& Ellis, G.B. (1981) Steroid-dependent and steroid-independent aspects of the photoperiodic control of seasonal reproductive cycles in male hamsters. In Biological Clocks in Seasonal Reproductive Cycles, pp. 251-260. Eds B. K. Follett \& D. E. Follett. Wright, Bristol.

Turek, F.W., Elliott, J.A., Alvis, J.D. \& Menaker, M. (1975) The interaction of castration and photoperiod in the regulation of hypophyseal and serum gonadotropin levels in male golden hamsters. Endocrinology 96, 854-860.

Urbanski, H.F. \& Follett, B.K. (1982) Photoperiodic modulation of gonadotrophin secretion in castrated Japanese quail. J. Endocr. 92, 73-83.

Received 24 December 1981 